\title{
Electromagnetic-Thermal Integration Design of Permanent Magnet Motor for Vehicles
}

\author{
Shijun Chen $\mathbb{D}^{1,2}$ Qi Zhang ${ }^{10}{ }^{1}$ and Surong Huang ${ }^{1}$ \\ ${ }^{1}$ School of Mechatronic Engineering and Automation, Shanghai University, Shanghai 200072, China \\ ${ }^{2}$ School of Physics and Electronic Engineering, Anqing Normal University, Anqing 246133, China \\ Correspondence should be addressed to Qi Zhang; qizhang@staff.shu.edu.cn
}

Received 13 December 2018; Accepted 28 March 2019; Published 2 May 2019

Academic Editor: M. Tariq Iqbal

Copyright (C) 2019 Shijun Chen et al. This is an open access article distributed under the Creative Commons Attribution License, which permits unrestricted use, distribution, and reproduction in any medium, provided the original work is properly cited.

\begin{abstract}
To more efficiently design high performance vehicular permanent magnet motor, an electromagnetic-thermal integration design method is presented, which considers both the electromagnetic properties and the temperature rise of motor winding when determining the main dimensional parameters of the motor. Then a 48-slot and 8-pole vehicular permanent magnet motor is designed with this method. The thermomagnetic coupling design is simulated and validated on the basis of multiphysical domain on finite element analysis. Then the prototype is analyzed and tested on a newly built motor experiment platform. It is shown that the simulation results and experimental results are consistent, which validate the accuracy and effectiveness of the new design method. Also this method is proved to well improve the efficiency of permanent magnet motor design.
\end{abstract}

\section{Introduction}

Vehicular permanent magnet motors are outstanding with high torque/current, high power density, high efficiency, and minitype light-weight. The urgent problems of motor design are how to reduce motor volume, save space, and improve material utilization rate while meeting specific performance indices. The design aims of vehicular permanent magnet motor should be high density, low weight, high reliability, high power at low-velocity, and constant-power wide-range speed control and to utmost increase the motor power density within limited space by enlarging the electromagnetic load. Thus, the size limit, electromagnetic load, and thermal load of vehicular motor are all far larger than common motor, and the temperature rise of motor becomes an extremely important indicator during vehicular permanent magnet motor design [1-3]. The traditional design methods of vehicular permanent magnet motor are to firstly design an electromagnetism scheme and thereby simulate temperature rise; the scheme is redesigned if the temperature rise is too high. This way is repeated until the electromagnetism scheme and motor temperature rise both are qualified. Admittedly, such design methods largely enlarge the workload of engineers and are less efficient. Thus, the electromagnetism design of vehicular permanent magnet motor should be integrated with the thermal design, forming an electromagnetic-thermal integration design (ETID) theoretical method for vehicular permanent magnet motor.

Currently, several methods for thermal analysis have been investigated in the literature. As reported, with a fluid-structure interaction finite element method (FEM), the steady-state temperature field of a $42 \mathrm{~kW}$ water-cooled vehicular permanent magnet synchronous motor under rated operating condition was simulated and analyzed [4]. A special cooling system and a new rotor structure prototype FEM model were built and were divided according to the heat production rate inside the motor and material properties [5]. A thermal magnetic coupling method for axial magnetic flux permanent magnet motor was proposed and used to segment the stators and rotors by using convection conduction analytical equations [6]. The thermal magnetic coupling of a double-salient-pole and double-rotor permanent magnet motor was analyzed by integrating thermal networks and FEM [7]. The lumped-parameter thermal network method and 3D fluid analysis were combined when the thermal effects of a surface-mounted permanent magnet motor with 
overhang structure were considered [8]. An electromagneticthermal-fluid integration analytical method was proposed for a permanent magnet synchronous motor [9]. A finite element package was used for the transient thermal analysis, under different load conditions and ambient temperatures, of a surface-mounted permanent magnet synchronous motor for aerospace actuation applications [10]. The thermal simulation model of in-wheel motor used for solar car was established, the thermal characteristics of in-wheel motor were analyzed by building the mass flow and heat-transfer coupling simulation model [11]. A new electrical-thermal two-way coupling design method was proposed to analyze the electromagnetic performances based on the investigated FSPM motor, where the change of PM material characteristics under different temperatures was taken into consideration [12]. A new AxialRadial Flux-Type Permanent Magnet Synchronous Motor was presented. The performance of Axial-Radial Flux-Type Permanent Magnet Synchronous Motor (ARFTPMSM) can be adjusted by changing Axial Magnetic Motive Force (AMMF). The three-dimensional steady-state temperature field distributions of ARFTPMSM under different AMMF were investigated by using time-stepping FEM [13].

Simultaneously, several methods of motor design also have been investigated in the literature. The design processes in electromagnetic aspect of a high-speed solid cylindrical PM motor equipped with magnetic bearings were presented [14]. The design of the 4-kW 150-krpm ultra-high-speed SPMSM for an electrically assisted turbocharger was presented [15]. A novel surface-mounted outer rotor transverse flux permanent magnet motor with simple structure and good performance was proposed, which improved the motor performance by transforming parts of the leakage flux into the main flux [16]. The rotor shapes of IPM motors for electric vehicles were analyzed and five types of motor rotors for automobiles were analyzed, including two hybrid vehicles [17].

The above studies suggest the existence of many practical and feasible methods for motor thermal performance computation and electromagnetic design. However, the thermal performance simulation in all methods is conducted after the motor electromagnetic scheme is determined, and there is rare research on ETID. In this paper, based on the basic theories of traditional motor electromagnetic design and thermal design, we proposed an ETID method for motor design. The effectiveness and superiority of this method were validated by using a newly built 48 -slot and 8-pole vehicular water-cooled permanent magnet motor.

\section{Generalized Equations of ETID}

2.1. Computation of Motor Main Dimensions. When the electromagnetic load, effective core length or length-diameter ratio, armature-phase voltage and phase current waveform coefficient, magnetic field waveform coefficient, and winding factor are all constant, the electromagnetic torque $T_{e m}$ of the motor is decided by the motor armature inner diameter and can be computed as follows [18]:

$$
T_{e m}=\frac{\pi K_{i} K_{N M} K_{d p} D_{i s}^{2} l_{e f} A B_{\delta}}{2}
$$

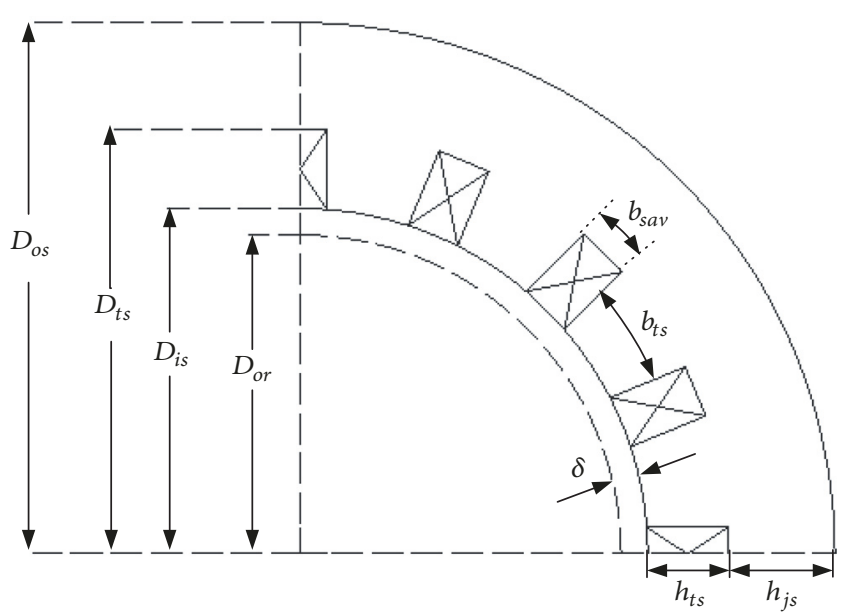

FIgURE 1: Stator structure of permanent magnet motor for vehicle.

where $K_{i}$ is the motor phase current waveform coefficient, $K_{N M}$ is the magnetic field waveform coefficient, $K_{d p}$ is the winding factor, $D_{i s}$ is the motor stator inner diameter, $l_{e f}$ is the effective stator core length, $A$ is the line load, and $B_{\delta}$ is the peak value of air gap flux density.

The stator structure of permanent magnet motor for vehicle is shown in Figure 1, where $D_{o s}$ is external diameter of motor stator, $D_{t s}$ is stator tooth root diameter, $D_{o r}$ is rotor diameter, $b_{t s}$ is stator tooth width, $b_{s a v}$ is the equivalent average slot width, $h_{j s}$ is stator yoke height, $h_{t s}$ is tooth height and equal to the equivalent average slot height $h_{s a v}$, and $\delta$ is air gap thickness. As seen in Figure 1,

$$
\begin{aligned}
& h_{t s}=\frac{D_{t s}-D_{i s}}{2} \\
& h_{j s}=\frac{D_{o s}-D_{t s}}{2}
\end{aligned}
$$

The ratio of $B_{\delta}$ to the calculated diameter of stator teeth flux density $B_{t s}$ and yoke flux density $B_{j s}$ is, respectively,

$$
\begin{aligned}
& k_{t s}=\frac{B_{\delta}}{B_{t s}} \\
& k_{j s}=\frac{B_{\delta}}{B_{j s}}
\end{aligned}
$$

The total air gap flux of permanent magnet motor for vehicle is calculated as follows, where $\alpha^{\prime}{ }_{p}$ is the computation arc coefficient; $B_{\delta a v}$ is average air gap flux density:

$$
\begin{aligned}
\Phi_{t} & =\pi \alpha_{p}^{\prime} D_{i s} l_{e f} B_{\delta} \\
\alpha_{p}^{\prime} & =\frac{B_{\delta a v}}{B_{\delta}}
\end{aligned}
$$

The total tooth area and slot area at the calculated diameter of stator teeth of vehicle permanent magnet motor are calculated as follows, where $k_{l s}$ is the core length coefficient 
and usually is approximated to $1, J_{s}$ is the stator winding current density, and $S_{f}$ is the coil space factor:

$$
\begin{aligned}
\sum s_{t s} & =\sum b_{t s} * h_{t s}=\frac{\Phi_{t} h_{t s}}{K_{F e s} l_{F e s} B_{t s}} \\
& =\frac{\pi \alpha_{p}^{\prime} k_{t s} D_{i s}\left(D_{t s}-D_{i s}\right)}{2 K_{F e s} k_{l s}} \\
\sum s_{s s} & =\frac{\pi D_{i s} A}{J_{s} S_{f}}
\end{aligned}
$$

Since the area between the root of stator teeth and the inner diameter of stator equals the sum of the total teeth and slot area of stator, the following formula is obtained:

$$
\begin{aligned}
\sum s_{t s}+\sum s_{s s} & =\frac{\pi\left(D_{t s}^{2}-D_{i s}^{2}\right)}{4} \\
& =\frac{\pi \alpha_{p}^{\prime} k_{t s} D_{i s}\left(D_{t s}-D_{i s}\right)}{2 K_{F e s} k_{l s}}+\frac{\pi D_{i s} A}{J_{s} s_{f}}
\end{aligned}
$$

The quadratic equation of stator inner diameter with respect to stator outer diameter of vehicle permanent magnet motor is obtained:

$$
A_{i s}^{o s} D_{o s}^{2}-2 B_{i s}^{o s} D_{o s}+C_{i s}^{o s}=0
$$

Solution:

$$
D_{i s}=f\left(D_{o s}\right)=\frac{B_{i s}^{o s} \pm \sqrt{B_{i s}^{o s}-A_{i s}^{o s} C_{i s}^{o s}}}{A_{i s}^{o s}}
$$

where

$$
\begin{aligned}
& A_{i s}^{o s}=\frac{\pi^{2} \alpha_{p}^{2} k_{j s}^{2}}{4 p^{2} K_{F e s}^{2} k_{l s}^{2}}+\frac{\alpha_{p}^{2} k_{j s} k_{t s}}{p K_{F e s}^{2} k_{l s}^{2}}+\frac{2 \alpha_{p}^{\prime} k_{t s}}{K_{F e s} k_{l s}}-1 \\
& B_{i s}^{o s}=\left(k_{t s}+\frac{\pi k_{j s}}{2 p}\right) \frac{\alpha_{p}^{\prime}}{K_{F e s} k_{l s}} D_{O S}+\frac{2 A}{J_{s} S_{f}} \\
& C_{i s}^{o s}=D_{o s}^{2}
\end{aligned}
$$

where $k_{j s}$ is the ratio of peak flux density in air gap to the flux density at stator yoke; $k_{t s}$ is the ratio of the flux density in air gap to the flux density in the stator tooth; $K_{F e s}$ is the core stacking coefficient; $p$ is the number of pole pairs; $J_{s}$ is the stator winding current density; and $S_{f}$ is the coil space factor.

The stator tooth width $b_{t s}$ can be computed as follows:

$$
b_{t s}=\frac{\pi \alpha_{p}^{\prime} k_{t s} D_{i s}}{Z_{s} K_{F e s} k_{l s}}
$$

where $Z_{s}$ is the stator slot number.

2.2. Computation of Temperature. Rise in Stator Slots. During motor designing, generally the winding heat is the most nondissipatable, and usually the temperature rise of all other parts can be satisfactory as long as the temperature rise of winding is qualified.

The stator slot was divided into 4 zones of winding, slot wedge, insulating paper, and slot wall gaps. The impregnating varnish and fine air gap inside the slots were successively and evenly assigned to the outer layer of each varnished wire composed of bare copper wire and varnish film. In other words, one bare copper wire, wire varnish film layer cylindrical walls, impregnating varnish layer cylindrical walls, and fine air gap cylindrical walls together constituted an equivalent conductor, and the $N$ equivalent conductors in each slot constituted a winding. Regarding the winding as a heat source, its equivalent thermal conductivity coefficient was calculated as follows [19]:

$$
\lambda_{s e}=\frac{1}{1 / \lambda_{0}+2 \sum_{i=1}^{n}\left(1 / \lambda_{i}\right) \ln \left(R_{i} / R_{i-1}\right)}
$$

where $\lambda_{s e}$ is the equivalent thermal conductivity coefficient inside the stator slot; $R_{0}$ and $\lambda_{0}$ are the radius and thermal conductivity coefficient of bare copper wire, respectively; $R_{n}$ is the radius of the outmost circle; $R_{i}$ and $\lambda_{i}$ are the radius and thermal conductivity coefficient of inner walls in the $i$-th layer in the middle, respectively; here $n=3 ; R_{1}, R_{2}$, and $R_{3}$ are the radii of the varnish film layer, the impregnating varnish layer, and the fine air gap layer, respectively. $R_{1}, R_{2}$, and $R_{3}$ can be calculated as follows [19]:

$$
\begin{aligned}
& R_{1}=R_{0}+d_{w} \\
& R_{2}=K_{L}\left(R_{3}-R_{1}\right)+R_{1} \\
& R_{3}=\sqrt{\frac{A_{\text {area }}-C_{\text {solt }}\left(\delta_{a}+d_{\text {in }}\right)}{N \pi}}
\end{aligned}
$$

where $\delta_{a}$ is the thickness of slot wall gaps; $d_{i n}$ is the thickness of insulation paper; $K_{L}$ is the varnish filling coefficient; $A_{\text {area }}$ and $C_{\text {slot }}$ are the slot area and slot perimeter except the slot wedge, respectively; and both are decided by the average slot length $h_{\text {sav }}$ and the average slot width $b_{\text {sav }}$. After substituting into (11), the equivalent thermal conductivity inside the stator slot can be calculated.

The stator slot thermal resistance consists of radial, circumferential, and axial parts of thermal resistance. Since the copper loss mainly conducts from inner to outer, here only the temperature rise of radial thermal resistance was considered. The thermal resistance $R_{\text {th_all }}$ inside a slot can be calculated as follows [20]:

$$
\begin{aligned}
R_{\text {th_all }}= & \frac{\left(h_{\text {sav }}-2 d_{\text {in }}-2 \delta_{a}\right) / 2}{\lambda_{s e} l_{\text {ef }}\left(b_{\text {sav }}-2 d_{\text {in }}-2 \delta_{a}\right)} \\
& +\frac{d_{\text {in }}}{\lambda_{\text {in }} l_{\text {ef }}\left(b_{\text {sav }}-2 \delta_{a}\right)}+\frac{\delta_{a}}{\lambda_{a} l_{e f} b_{\text {sav }}}
\end{aligned}
$$

where $\lambda_{\text {in }}$ is the thermal conductivity coefficient of insulation paper; $\lambda_{a}$ is the thermal conductivity coefficient of air. Thus, the temperature rise inside each slot can be calculated as follows:

$$
\Delta \theta_{w}=\frac{P_{c u}}{Z_{s}} \times R_{t h\lrcorner a l l}
$$




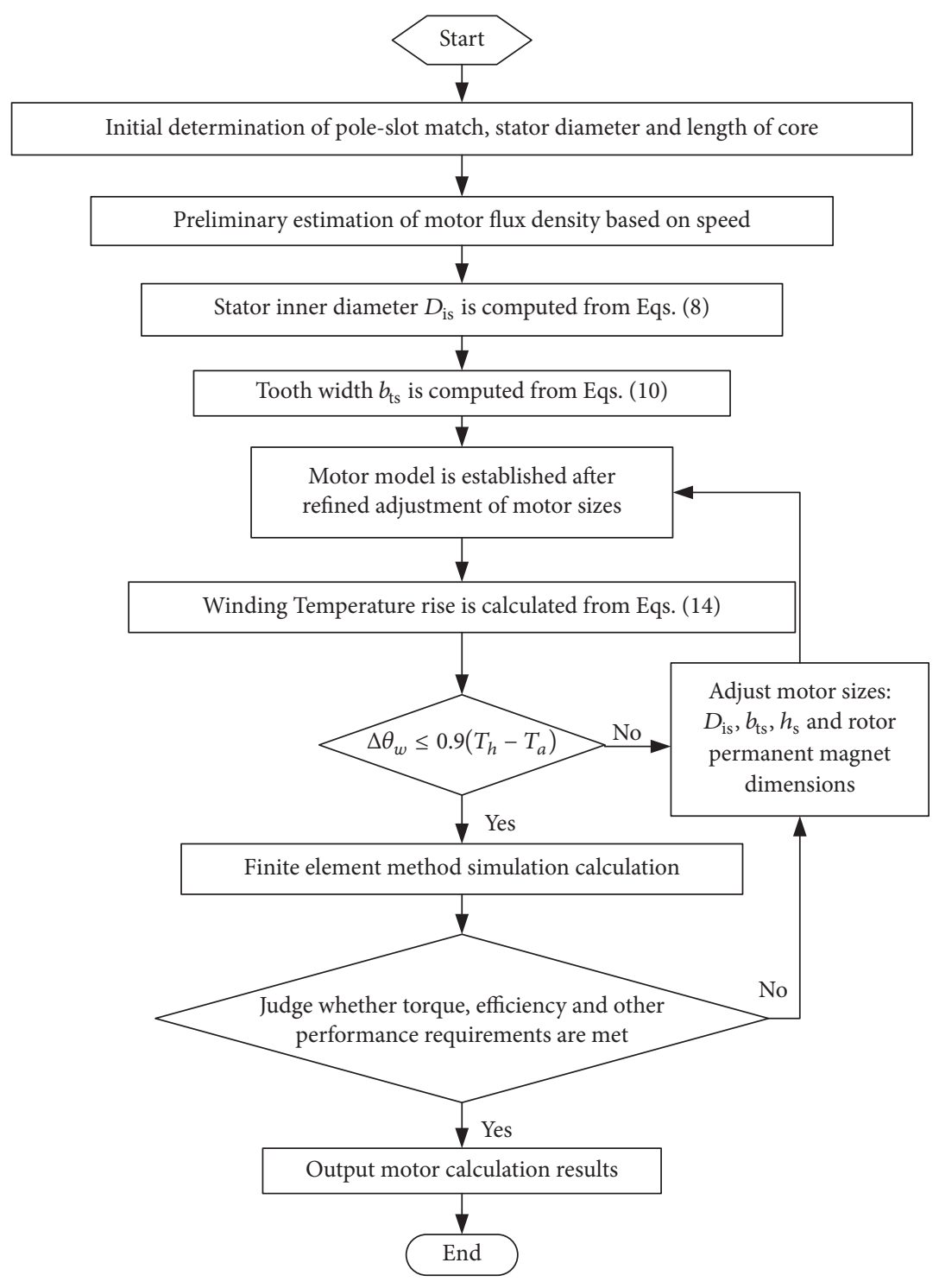

FIGURE 2: Electromagnetic-thermal integration design process.

where $P_{c u}$ is copper loss and can be empirically calculated according to the motor efficiency requirements and engineering design. Clearly, under the same copper loss, when the coil space factor, slot insulation thickness, thermal conductivity coefficients of slot insulation, impregnating varnish, and varnish films, and varnish filling coefficient are all constant, the temperature rise of the stator slot is directly proportional to the slot equivalent height $h_{\text {sav }}$, but is inversely proportional to the slot equivalent width $b_{\text {sav }}$ and the stator core length $l_{e f}$. According to experience, at the ambient temperature $T_{a}>40^{\circ} \mathrm{C}$, the permitted temperature rise of motor winding should meet the following condition [21]:

$$
\Delta \theta_{w} \leq 0.9\left(T_{h}-T_{a}\right)
$$

where $T_{h}$ is the highest temperature and can be assigned with different empirical values according to the grade of insulation (e.g., A, B, F, H).
In sum, the major dimensional parameters of a motor not only relate to its electromagnetic performance, but also critically affect the temperature rise of motor winding.

\section{Key Technical Flow Chart of ETID}

The key technical flowchart of the ETID is illustrated in Figure 2. Firstly, according to the design requirements, appropriate pole-slot match is selected; the motor stator outer diameter and motor iron core length are determined; the flux density is estimated according to the preset rotating speed; the stator inner diameter and tooth breadth are computed from (8) and (10); after refined adjustment, the shape of the stator slot is determined. Secondly, the motor winding temperature rise is calculated and judged according to (14) and (15); if the requirements of temperature rise are unsatisfied, the motor inner diameter $D_{i s}$, tooth width $b_{t s}$, and 


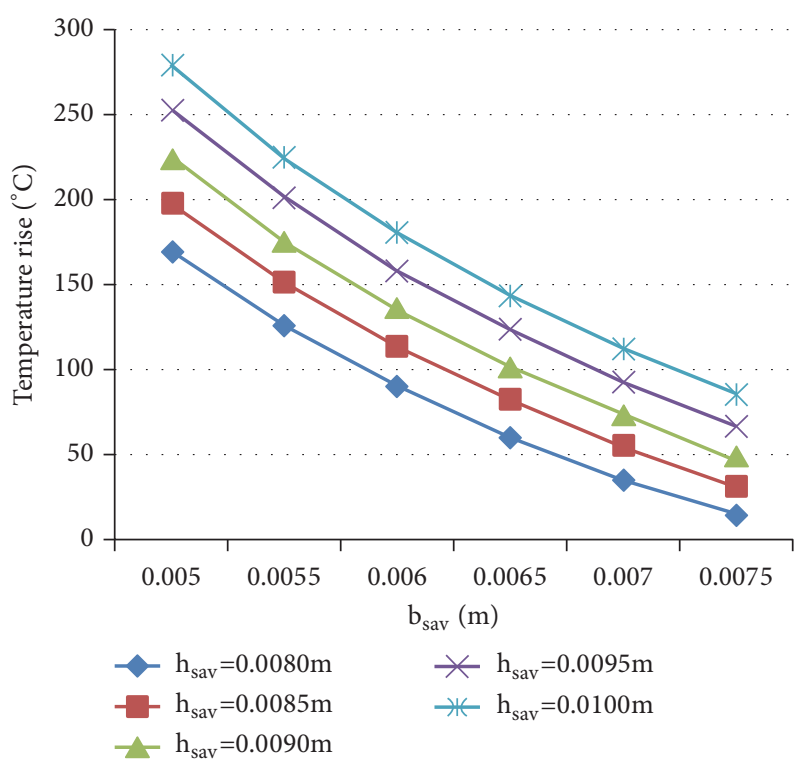

Figure 3: The curves of temperature rise in stator slot versus $b_{\text {sav }}$ and $h_{\text {sav }}$.

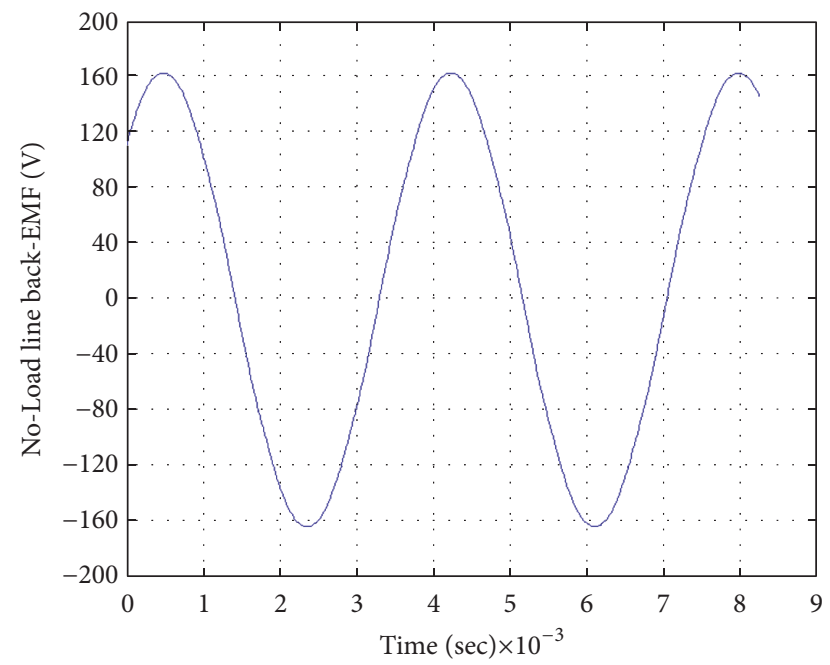

FIgURE 4: No-Load line back-EMF simulation waveform at 4000r/min.

slot height $h_{s}$ should be adjusted until the conditions are satisfied. Finally, an appropriate rotor magnetic steel structure is selected and a complete motor model is established for FEM computation; the electromagnetic torque, efficiency, and other performance indices of the motor are evaluated; if the design requirements are unsatisfied, the motor dimensions including rotor structure should be adjusted or refined until the design requirements are met.

\section{ETID Simulation on FEM}

According to the dimensional relation in Section 2.1, we set the outer diameter $230 \mathrm{~mm}$ as the baseline, pole-slot match $=48$-slot and 8-pole, waveform coefficient $K_{N m}=1.11$,

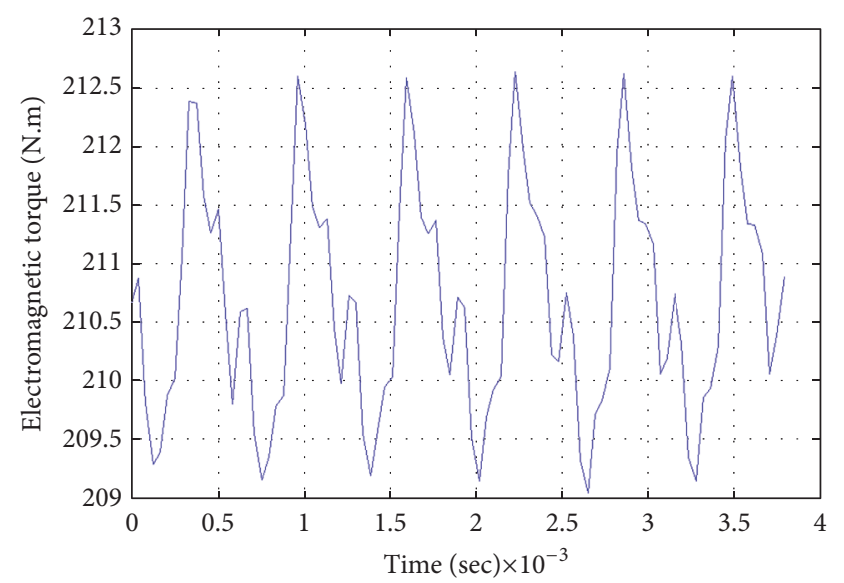

FIGURE 5: Electromagnetic torque simulation waveform at 4000r/min@88kW.

phase current waveform coefficient $K_{i}=1.414$, axial length $l_{\text {ef }}$ $=160 \mathrm{~mm}$, and rated rotating speed $n=4000 \mathrm{rpm}$ and thereby approximately estimated the electromagnetic density. The stator inner diameter $D_{i s}$ can be preliminarily estimated from (8). At the core stacking coefficient $K_{\text {Fes }}=0.97$ and $B_{\delta}=0.6 \mathrm{~T}$, we calculated the stator tooth width from (10).

According to formulas (13) and (14), the curves of temperature rise in stator slot versus the equivalent height and width of stator slot are obtained as shown in Figure 3. It can be seen that the temperature rise in the stator slot is proportional to the equivalent height of the stator slot $h_{s a v}$ and inversely proportional to the equivalent width of the slot $b_{\text {sav }}$. Considering that the insulation level of the prototype winding is $\mathrm{H}$ and the ambient temperature is $48^{\circ} \mathrm{C}$, the maximum temperature rise of the motor is estimated according to formula (15).

According to the above preliminary estimations, we designed a V-shaped rotor structure, appropriately refined the dimensional parameters, and designed the prototype machine with the performance and major dimensions showed in Table 1. The No-Load line back-EMF simulation waveform at $4000 \mathrm{r} / \mathrm{min}$ is illustrated in Figure 4, with the peak at $318 \mathrm{~V}$. The electromagnetic torque simulation waveform at 4000r/min@88kW is showed in Figure 5, with the average electromagnetic torque $210.7 \mathrm{~N} \bullet \mathrm{m}$.

Given the multiphysical domain of circuit, electromagnetism, fluid, and temperature and based on the coupling simulation of control circuit, electromagnetic calculation, and thermal analysis, we determined the temperature distributions of key motor parts of the vehicular permanent magnet motor at working condition 4000r/min@42kW and considering inverter harmonic loss (Figure 6[3]). The highest temperatures of water jacket, stator winding, stator core, rotor core, and permanent magnet were $49.5^{\circ} \mathrm{C}, 113.8^{\circ} \mathrm{C}, 114.8^{\circ} \mathrm{C}$, $122.2^{\circ} \mathrm{C}$, and $122.4^{\circ} \mathrm{C}$, respectively.

\section{Experimental Verification}

The test platform for prototype machine has been set up, as shown in Figure 7, in which two identical motors with the 


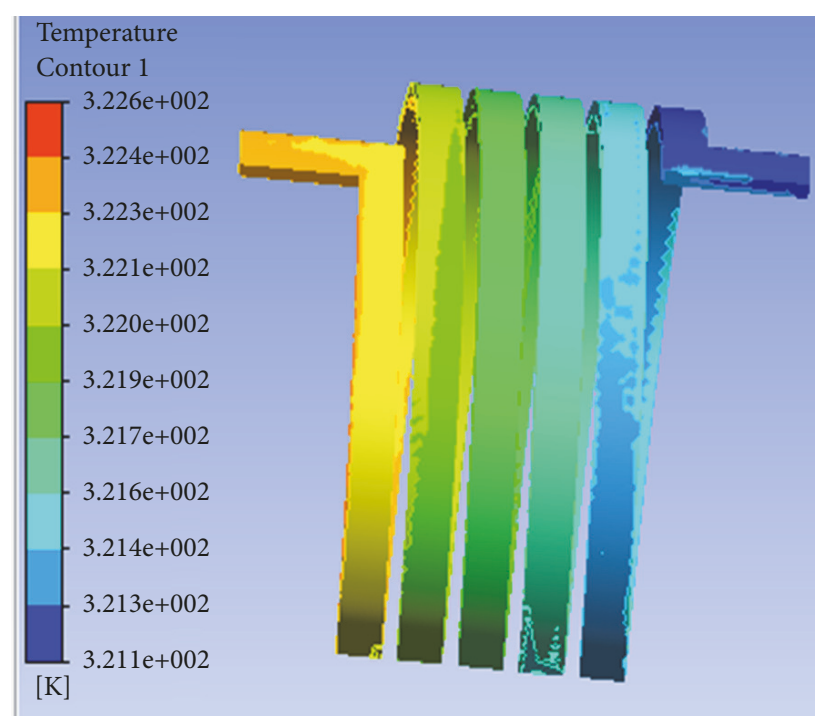

(a)

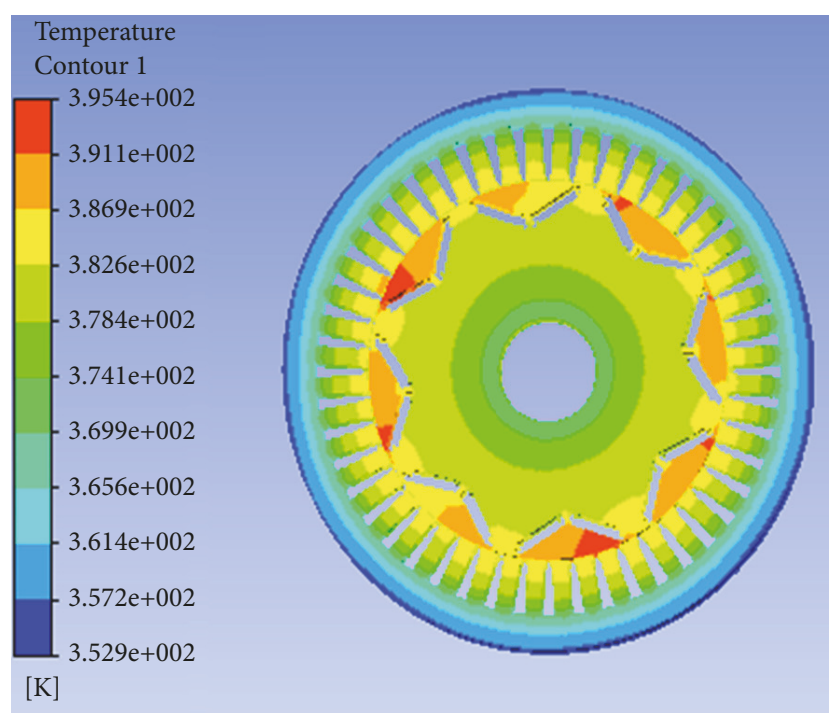

(c)

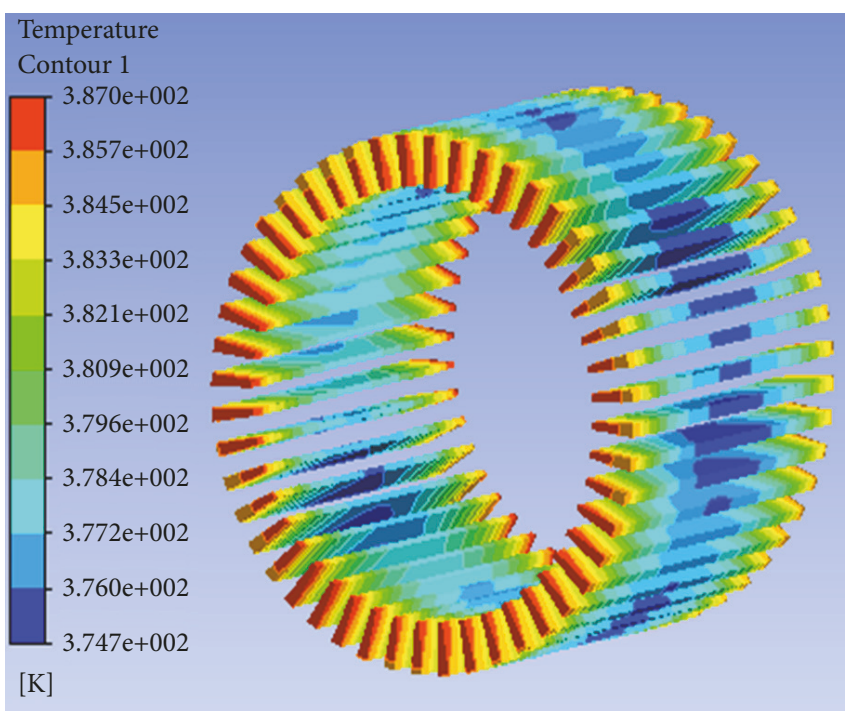

(b)

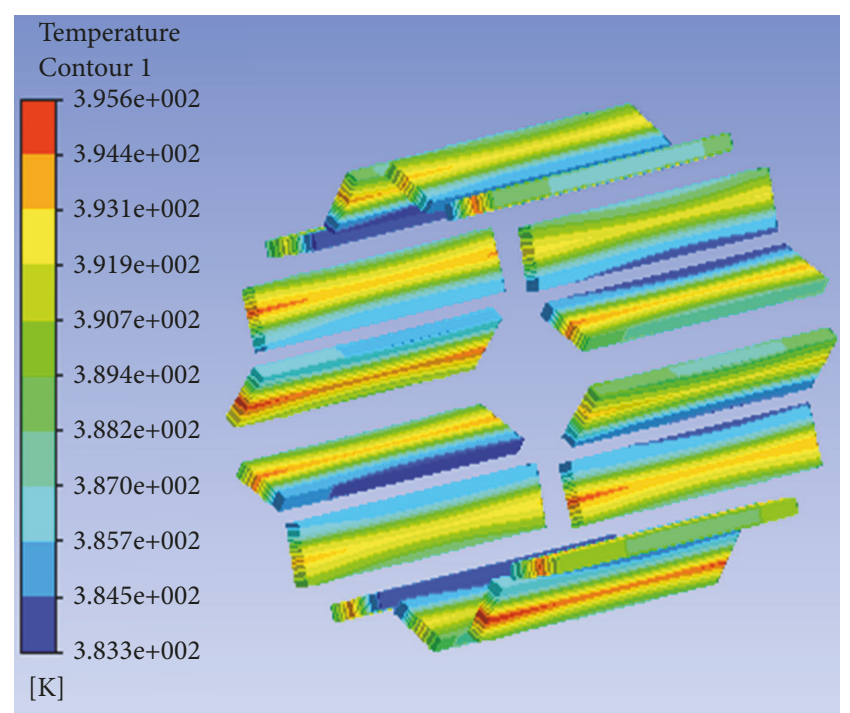

(d)

FIGURE 6: Temperature distribution after considering the harmonic loss: (a) water jacket; (b) stator winding; (c) stator and rotor core; (d) magnet.

rated power $42 \mathrm{~kW}$ are driven with each other. The tested motor adopts torque control while the other motor uses speed control. In addition, the cooling system is used in this experiment. With the purpose of monitoring temperature variation in each component, thermal resistors are, respectively, placed at the end winding of motor, the outer wall of frame, the underside of rotor permanent magnet, the water inlet, and the outlet of frame. The inlet water temperature is set for $48^{\circ} \mathrm{C}$ with the water flow rate $12 \mathrm{~L} / \mathrm{min}$.

The No-Load line back-EMF measured waveform at 4000r/min was showed in Figure 8, with the peak value at 322 V. Clearly, the experimental data are very consistent with the simulation results in terms of waveform amplitude and shape.

The current waveform experimentally measured at 4000r/min@88kW was showed in Figure 9. Since a current amplifier was used in the experiments, what the oscilloscope displayed was voltage signals. The voltage peak value was $1.064 \mathrm{~V}$, and the current voltage change ratio was $1 \mathrm{~A} / \mathrm{mV}$. After conversion, the peak current of the input motor was $1064 \mathrm{~A}$, or, namely, the current amplitude was $532 \mathrm{~A}$, the current advance angle $37^{\circ}$, and motor output torque 210.6 $\mathrm{Nm}$. The experimental results are very close to the simulation results.

The stator winding temperature and permanent magnet temperature measured at $4000 \mathrm{r} / \mathrm{min} @ 42 \mathrm{~kW}$ were $112^{\circ} \mathrm{C}$ and $123^{\circ} \mathrm{C}$, respectively, which were very close to the simulated results $\left(113.8^{\circ} \mathrm{C}, 122.4^{\circ} \mathrm{C}\right)$.

In all, the electromagnetic simulation results and thermal simulation results were very close to the experimentally measured results, indicating the vehicular permanent magnet 


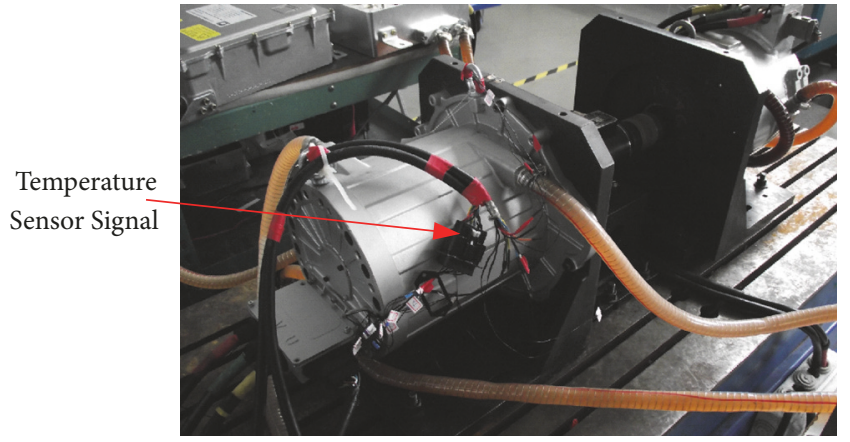

FIGURE 7: Test platform for prototype machine.

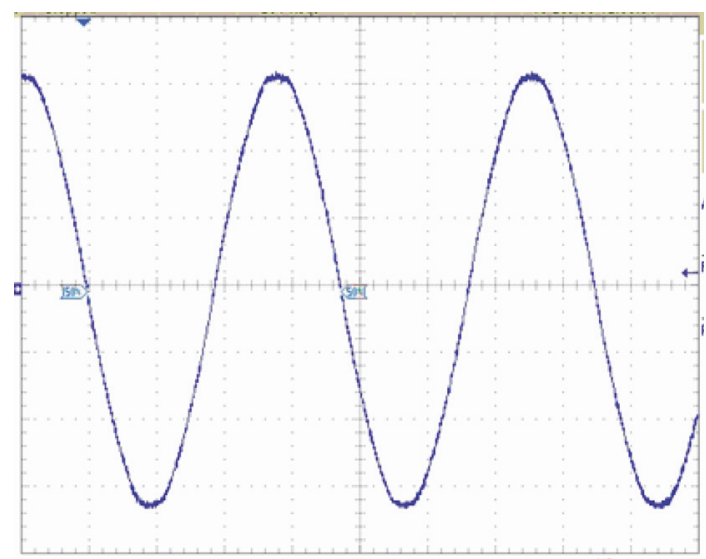

Figure 8: No-Load line back-EMF measured waveform at 4000r/min.

motor ETID method proposed here was accurate and effective.

\section{Conclusions}

An efficient vehicular permanent magnet motor ETID method was proposed, which integrated both electromagnetism design and temperature rise design and thereby largely shortened the motor schematic designing period and enhanced the efficiency.

(1) During motor design, the key dimensional parameters affecting motor electromagnetic performance included stator inner diameter and tooth width, equations of which were presented here.

(2) Temperature rise of motor stator winding was a key indicator of motor thermal performance. Here the intraslot winding thermal conductive coefficient was equivalently computed, and thereby the winding temperature rise was estimated. Together with the empirical value range of winding temperature rise, the thermal design of motor winding was conducted, which was highly practical.

(3) A 48-slot and 8-pole permanent magnet motor with the rated power $42 \mathrm{KW}$ was built for ETID. The experimental data were consistent with the simulated data. The motor ETID

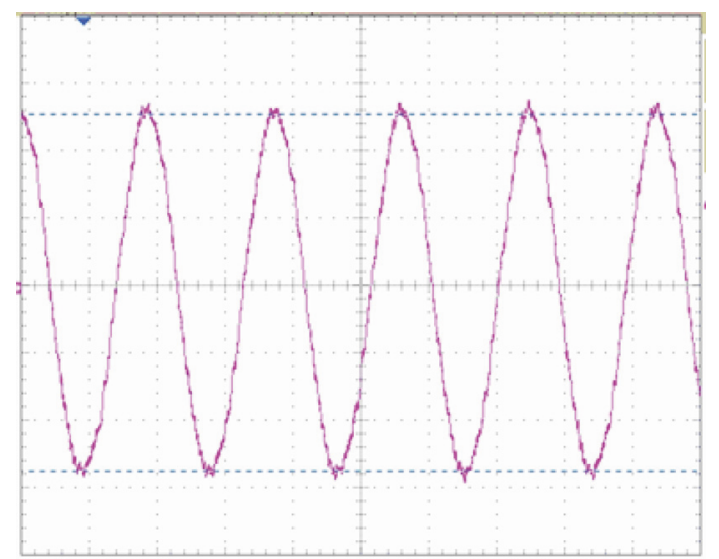

FIGURE 9: Measured waveform of input current at $4000 \mathrm{r} / \mathrm{min}$ @88kW.

TABle 1: Performance and main dimensions of prototype machine.

\begin{tabular}{lc}
\hline Parameters & Value \\
\hline Rated power $(\mathrm{kW})$ & 42 \\
Rated speed $(\mathrm{rpm})$ & 4000 \\
Maximum power $(\mathrm{kW})$ & 88 \\
Maximum speed $(\mathrm{rpm})$ & 11500 \\
Stator outer diameter $D_{o s}(\mathrm{~mm})$ & 230 \\
Stator inner diameter $D_{i s}(\mathrm{~mm})$ & 156.4 \\
Rotor inner diameter $(\mathrm{mm})$ & 43 \\
Pole/slot & $8 / 48$ \\
Core length $(\mathrm{mm})$ & 160 \\
Stator slot height $h_{s}(\mathrm{~mm}):$ & 20 \\
Tooth width $b_{t s}(\mathrm{~mm})$ & 6.54 \\
Air-gap length $(\mathrm{mm})$ & 0.6 \\
Winding insulation level & $\mathrm{H}$ \\
\hline
\end{tabular}

method was proved effective, accurate, and excellent and provides effective means for practical engineering applications.

\section{Data Availability}

The nature of the data is the motor size parameters; the data can be accessed from Electrical Machinery Laboratory of Shanghai University. The complete data belong to the joint ownership of the Electrical Machinery Laboratory of Shanghai University and the enterprise.

\section{Conflicts of Interest}

The authors declare no conflicts of interest.

\section{Acknowledgments}

This work was supported by the National Natural Science Foundation of China under Grant no. 61572238 and the Shanghai Industry-University-Institute Cooperation Annual Plan Project under Grant no. Hu CXY-2015-014. 


\section{References}

[1] T. D. Kefalas and A. G. Kladas, “Thermal investigation of permanent-magnet synchronous motor for aerospace applications," IEEE Transactions on Industrial Electronics, vol. 61, no. 8, pp. 4404-4411, 2014.

[2] H. Xuzhen, L. Jiaxi, Z. Chengming, and L. Liyi, "Calculation and experimental study on temperature rise of a high overload tubular permanent magnet linear motor," IEEE Transactions on Plasma Sciences, vol. 41, no. 5, pp. 1182-1187, 2013.

[3] S. J. Chen, Q. Zhang, B. He, S. R. Huang, and D.-D. Hui, “Thermal analysis of high density permanent magnet synchronous motor based on multi physical domain coupling simulation," Journal of Electrical Engineering \& Technology, vol. 12, no. 1, pp. 91-99, 2017.

[4] Z. Qi, W. Weixu, H. Surong, and G. Jianwen, "Heat tansfer simulation of high density permanent magnet motor for vehicles based on fluid-solid coupling method," Electric Machines \& Control Application, vol. 8, pp. 86-90, 2012.

[5] A. M. El-Refaie, J. P. Alexander, S. Galioto et al., "Advanced high power-density interior permanent magnet motor for traction applications," in Proceedings of the 2013 IEEE Energy Conversion Congress and Exposition, pp. 581-590, IEEE, USA, September 2013.

[6] H. Vansompel, A. Rasekh, A. Hemeida, J. Vierendeels, and P. Sergeant, "Coupled electromagnetic and thermal analysis of an axial flux PM machine," IEEE Transactions on Magnetics, vol. 51, no. 11, Article ID 8108104, 2015.

[7] Y. Chen, X. Zhu, L. Quan, and L. Wang, "Performance analysis of a double-salient permanent-magnet double-rotor motor using electromagnetic-thermal coupling method," IEEE Transactions on Applied Superconductivity, vol. 26, no. 4, Article ID 5205305, 2016.

[8] H. K. Yeo, H. J. Park, J. M. Seo, S. Y. Jung, J. S. Ro, and H. K. Jung, "Electromagnetic and thermal analysis of a surfacemounted permanentmagnet motor with overhang structure," IEEE Transactions on Magnetics, vol. 53, no. 6, Article ID 8203304, 2017.

[9] Y. Jiang, D. Wang, J. Chen, Q. Zhang, and T. Xuan, "Electromagnetic-thermal-fluidic analysis of permanent magnet synchronous machine by bidirectional method," IEEE Transactions on Magnetics, vol. 54, no. 3, Article ID 8102705, 2018.

[10] T. D. Kefalas and A. G. Kladas, "Finite element transient thermal analysis of PMSM for aerospace applications," in Proceedings of the 2012 20th International Conference on Electrical Machines, ICEM 2012, pp. 2566-2572, France, September 2012.

[11] F.-X. Yao, Z.-K. Zhang, and Y.-T. Zhang, "Simulation researches on thermal characteristics of vehicular in-wheel motors," in Proceedings of the 3rd 2017 International Conference on Sustainable Development (ICSD 2017), pp. 329-335, Tianjin, China, July 2017.

[12] Z. Shu, X. Zhu, L. Quan, Y. Du, and C. Liu, "Electromagnetic performance evaluation of an outer-rotor flux-switching permanent magnet motor based on electrical-thermal two-way coupling method," Energies, vol. 10, no. 5, article 677, 2017.

[13] D. Li, Y. Wen, W. Li, B. Feng, and J. Cao, "Three-dimensional temperature field calculation and analysis of an axial-radial flux-type permanent magnet synchronous motor," Energies, vol. 11, no. 5, article 1208, 2018.

[14] S. Xu, X. Liu, and Y. Le, "Electromagnetic design of a highspeed solid cylindrical permanent-magnet motor equipped with active magnetic bearings," IEEE Transactions on Magnetics, vol. 53, no. 8, Article ID 8203715, 2017.

[15] M.-S. Lim, J.-M. Kim, Y.-S. Hwang, and J.-P. Hong, "Design of an ultra-high-speed permanent-magnet motor for an electric turbocharger considering speed response characteristics," IEEE/ASME Transactions on Mechatronics, vol. 22, no. 2, pp. 774-784, 2017.

[16] D. Xianming, "Design and performance analysis of a novel transverse flux permanent-magnet motor," International Journal of Applied Electromagnetics \& Mechanics, vol. 56, pp. 623635, 2018.

[17] M.-H. Hwang, J.-H. Han, D.-H. Kim, and H.-R. Cha, "Design and analysis of rotor shapes for IPM motors in EV power traction platforms," Energies, vol. 11, no. 10, article 2601, 2018.

[18] Z. Xiang, Electric Excitation/PM BSG Synchronous Motor in Vehicle Design Theory and Simulation Comparison, Shanghai University, Shanghai, China, 2016.

[19] Z. Qi, L. Xirui, H. Surong, and Z. Jun, “Temperature rise calculations of high density permanent magnet motors based on multidomain co-simulation," Proceedings of the CSEE, vol. 34, no. 12, pp. 1874-1881, 2014.

[20] G. Huang and F. Fu, Small And Medium Sized Rotary Motor Design Manual, China Electric Power Press, 2014.

[21] E. Levi, Polyphase Motors, chap.10, Wiley, 1986. 


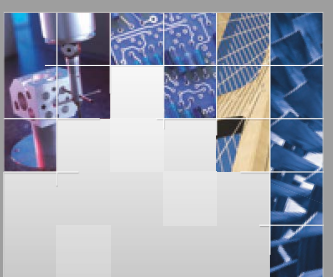

\section{Enfincering}
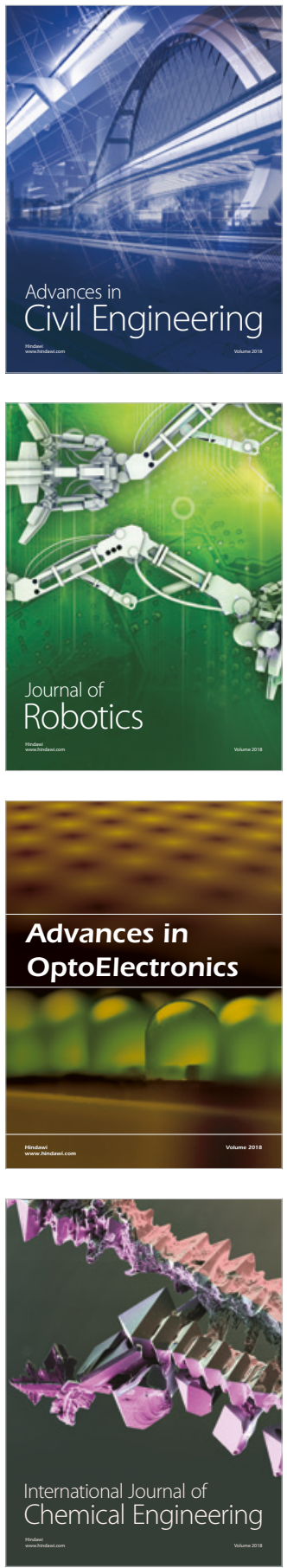

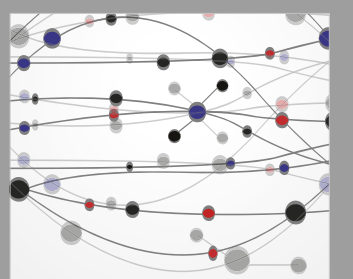

\section{Rotating \\ Machinery}

The Scientific World Journal

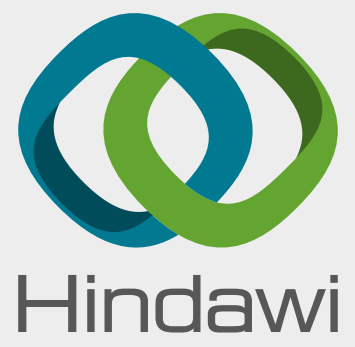

Submit your manuscripts at

www.hindawi.com
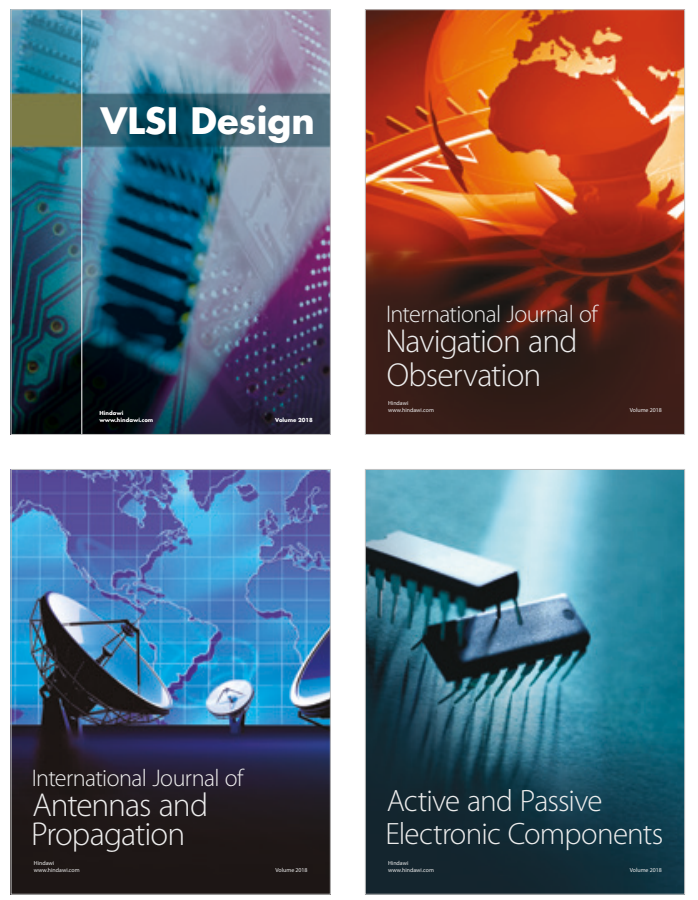
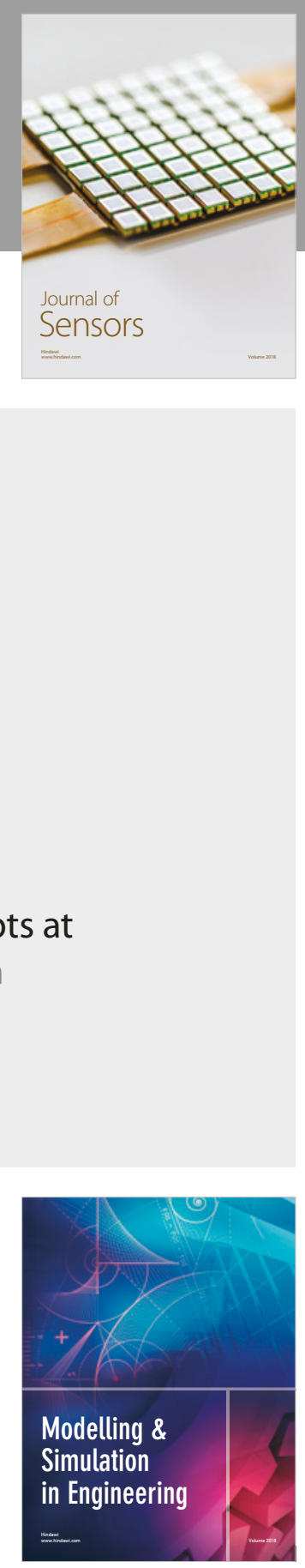

\section{Advances \\ Multimedia}
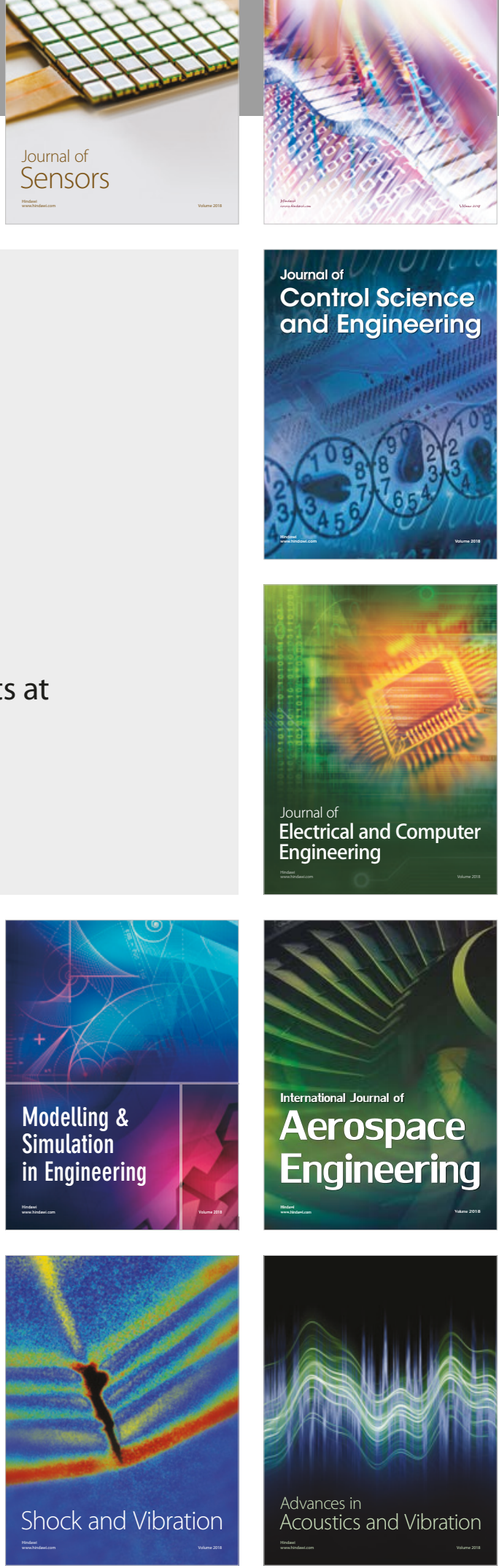